\title{
Geobacteraceae are important members of mercury-methylating microbial communities of sediments impacted by waste water releases
}

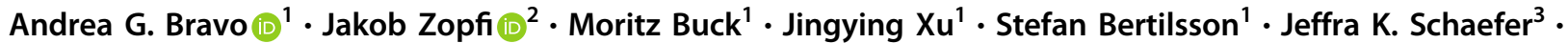 \\ John Poté ${ }^{4} \cdot$ Claudia Cosio $\mathbb{1}^{4,5}$
}

Received: 19 May 2017 / Revised: 29 September 2017 / Accepted: 18 October 2017 / Published online: 10 January 2018

(c) The Author(s) 2018. This article is published with open access

\begin{abstract}
Microbial mercury $(\mathrm{Hg})$ methylation in sediments can result in bioaccumulation of the neurotoxin methylmercury (MMHg) in aquatic food webs. Recently, the discovery of the gene $\mathrm{hgcA}$, required for $\mathrm{Hg}$ methylation, revealed that the diversity of $\mathrm{Hg}$ methylators is much broader than previously thought. However, little is known about the identity of Hg-methylating microbial organisms and the environmental factors controlling their activity and distribution in lakes. Here, we combined high-throughput sequencing of 16S rRNA and $h g c A$ genes with the chemical characterization of sediments impacted by a waste water treatment plant that releases significant amounts of organic matter and iron. Our results highlight that the ferruginous geochemical conditions prevailing at $1-2 \mathrm{~cm}$ depth are conducive to $\mathrm{MMHg}$ formation and that the $\mathrm{Hg}$ methylating guild is composed of iron and sulfur-transforming bacteria, syntrophs, and methanogens. Deltaproteobacteria, notably Geobacteraceae, dominated the $h g c A$ carrying communities, while sulfate reducers constituted only a minor component, despite being considered the main $\mathrm{Hg}$ methylators in many anoxic aquatic environments. Because iron is widely applied in waste water treatment, the importance of Geobacteraceae for $\mathrm{Hg}$ methylation and the complexity of $\mathrm{Hg}$ methylating communities reported here are likely to occur worldwide in sediments impacted by waste water treatment plant discharges and in iron-rich sediments in general.
\end{abstract}

Electronic supplementary material The online version of this article (https://doi.org/10.1038/s41396-017-0007-7) contains, which is available to authorized users.

$\triangle$ Claudia Cosio

claudia.cosio@univ-reims.fr

1 Limnology and Science for Life Laboratory, Uppsala University, Uppsala SE-75236, Sweden

2 Aquatic and Stable Isotope Biogeochemistry, University of Basel, Basel CH-4056, Switzerland

3 Environmental Sciences, Rutgers University, New Brunswick, NJ 08901, USA

4 Environmental Biogeochemistry and Ecotoxicology, University of Geneva, Geneva CH-1205, Switzerland

5 Present address: Unité Stress Environnementaux et BIOSurveillance des Milieux Aquatiques UMR-I 02 (SEBIO), Université de Reims Champagne Ardenne, Reims F-51687, France

\section{Introduction}

Methylmercury (MMHg) is a neurotoxin that is biomagnified in aquatic food webs with fish consumption as a primary route for human $\mathrm{MMHg}$ exposure [1]. In aquatic ecosystems, methylation of mercury $(\mathrm{Hg})$ to $\mathrm{MMHg}$ is carried out by microorganisms that are usually present at oxic-anoxic boundaries of sediments [2], water columns [3] and settling particles [4]. Studies on sediments have implicated sulfate-reducing bacteria (SRB) as the main contributors to MMHg formation, as inhibition of SRB with molybdate often decreases MMHg production rates [5-9]. Accordingly, many studies have aimed to identify the SRB strains responsible for $\mathrm{Hg}$ methylation by testing their $\mathrm{Hg}$ methylating potential in pure cultures $[10,11]$, or by determining correlations between $\mathrm{Hg}$ methylation and the presence of SRB markers in sediments $[12,13]$ or water column [5]. Few studies have however linked Hg methylation to iron-reducing bacteria (FeRB) $[14,15]$, or methanogenic archaea [16]. The identification of the genes $(h g c A B)$ required for $\mathrm{Hg}$ methylation [17] led to the 
discovery that the diversity of $\mathrm{Hg}$ methylators was much broader and the process more complex than previously thought [18]. Notably, the ability to methylate Hg has been identified within new phyla (Firmicutes and Chloroflexi) featuring also fermentative and acetogenic metabolisms [17-19]. The discovery of genetic markers for $\mathrm{Hg}$ methylation also opened the door to more efficient, standardized, and detailed monitoring of $\mathrm{Hg}$ methylators in the environment. Accordingly, microbial Hg-methylating communities have recently been described in wetlands and paddy soils and included methanogens, SRB, FeRB, and syntrophs [19-22]. Hg-methylating microbial communities in lakes, on the other hand, remain poorly investigated with regards to the types of microorganisms involved and the factors influencing their activities, except that MMHg formation is determined by the molecular composition of organic matter $(\mathrm{OM})$ [23].

Waste production can have a strong impact on the chemical and biological characteristics of freshwaters [24, 25]. As an example, treated waste water from the City of Lausanne is discharged into Lake Geneva (Switzerland) via an outlet pipe located in Vidy Bay. The dephosphatation treatment, based on the addition of ferric chloride to the waste water, causes enhanced inputs of $\mathrm{Fe}$ into the bay $[24,26]$. Moreover, the current volume of sewage exceeds the capacity of the waste water treatment plant (WWTP), requiring transient releases of partially untreated water, which contributes to the enrichment of the sediments with $\mathrm{OM}$ and various trace metals [27]. Among them $\mathrm{Hg}$ is of major concern because of its toxicity and the high ambient concentrations (e.g., refs. [2, 25]). Previous studies have shown that the areas affected by the WWTP discharge are hotspots for MMHg formation and concentration [2]. In particular, it was found that sediments enriched in OM with prevailing ferruginous conditions (i.e., high concentrations of dissolved $\mathrm{Fe}^{\mathrm{II}}$ and no free sulfide in the porewater) had the highest $\mathrm{Hg}$ methylation rates found in the bay [2]. Furthermore, sediment amendment experiments revealed that inhibition of dissimilatory sulfate reduction with molybdate led to increased Fereduction rates and enhanced $\mathrm{Hg}$ methylation. It was thus concluded that microorganisms other than SRB were responsible for $\mathrm{Hg}$ methylation [2], but the identity of the Hg-methylating microorganisms and thus the pathways by which $\mathrm{MMHg}$ was formed were not elucidated.

Building on this earlier discovery and recognizing the potential global implications of enhanced $\mathrm{Hg}$ methylation rates in WWTP-influenced sediments, the aim of this study was to provide a mechanistic understanding of $\mathrm{MMHg}$ formation in Fe-rich freshwater sediments. For this purpose, we linked sediment geochemistry and $\mathrm{Hg}$ speciation with parallel analysis of the genes coding for 16S rRNA and $h g c A$. In addition, the functional potential of the microbial communities was assessed by qPCR quantification of specific genes involved in the biogeochemical cycling of carbon, sulfur and iron. This is the first study in WWTPimpacted sediments exploring the diversity of microorganisms involved in $\mathrm{Hg}$ methylation.

\section{Material and methods}

\section{Study site and sampling}

The present study was conducted in the Vidy Bay of Lake Geneva, one of the largest freshwater reservoirs in Europe. Samples were collected at a site close to the WWTP outlet pipe (CP, 46 $\left.30^{\circ} 52.89^{\prime \prime} \mathrm{N}, 6^{\circ} 35^{\prime} 21.25^{\prime \prime} \mathrm{E}\right)$ based on previous studies showing a strong impact of the WWTP on MMHg formation [2]. Three replicate sediment cores (A, B, and C) were collected in August 2010 as detailed in the Supplementary Information.

\section{Chemical analysis}

Total carbon, organic carbon $\left(\mathrm{C}_{\mathrm{org}}\right)$, inorganic carbon ( $\mathrm{C}_{\text {inorg; }}$ samples exposed twice to $5 \% \mathrm{H}_{3} \mathrm{PO}_{4}$ overnight) and nitrogen $\left(\mathrm{N}_{\text {tot }}\right)$ in sediments were measured with a $\mathrm{CHN}$ elemental analyzer (Perkin Elmer 2400 series II). OM content was determined by loss on ignition (LOI) [28].

Metals were extracted from freeze-dried sediment with $2 \mathrm{~N}$ $\mathrm{HNO}_{3}$ at $100{ }^{\circ} \mathrm{C}$ for $12 \mathrm{~h}$. Total $\mathrm{Fe}$ and $\mathrm{S}\left(\mathrm{Fe}_{\text {tot }} ; \mathrm{S}_{\text {tot }}\right)$ were measured by ICP-AOS (iCAP-6300 Duo Thermo Scientific). A detailed description of mercury speciation and quantification can be found elsewhere [2]. Briefly, sediment total $\mathrm{Hg}\left(\mathrm{Hg}_{\text {tot }}\right)$ was quantified using an Advanced Mercury Analyser (254 Altec). MMHg in sediments was extracted by $\mathrm{HNO}_{3}$ leaching/ $\mathrm{CH}_{2} \mathrm{Cl}_{2}$ extraction and measured by ethylation onto Tenex traps followed by GC separation [29]. $\mathrm{Hg}_{\text {tot }}$ in porewater was measured by CV-AFS [30]. MMHg in porewater was measured by species-specific isotope dilution and GC-ICPMS [31].

Porewater concentrations of $\mathrm{SO}_{4}{ }^{2-}$ and $\mathrm{NO}_{3}{ }^{-}$were analyzed by ion-chromatography (Dionex ICS-3000) with an IonPac_AS19 column. Poorly crystalline $\mathrm{Fe}^{\mathrm{III}}$-oxides in the sediment were extracted with $0.5 \mathrm{M} \mathrm{HCl}$, reduced to $\mathrm{Fe}^{\mathrm{II}}$ with $1 \mathrm{M}$ hydroxylamine hydrochloride and subsequently quantified with the ferrozine method [32]. Elemental sulfur $\left(S^{0}\right)$ was extracted from wet sediment with methanol and subsequently analyzed by RP-HPLC and UV detection at $265 \mathrm{~nm}$ [33].

\section{DNA extraction and bacterial community composition: 16S rRNA gene}

DNA was extracted in triplicate from freeze-dried sediments with the Power Soil DNA Extraction kit (Mo-Bio) as previously described [34]. PCR primers $341 \mathrm{~F}$ (5'-CCTACG GGNGGCWGCAG-3') and 805 R (5'-GACTACHVGGG 
TATCTAATCC-3') were used for amplification of the $16 \mathrm{~S}$ rRNA gene from most bacteria $[35,36]$. The resulting PCR products were used as template in an additional 10-cycle amplification with sample-specific barcoded primers according to Sinclair et al. [37]. See Supplementary Table 1 and Supplementary Information for details.

Amplicon sequencing data (Illumina MiSeq pair-end $300 \mathrm{bp}$ ) were preprocessed using FastQC [38] and the illumitag pipeline as described in Sinclair et al. [37]. Chimeric sequences were removed and reads were grouped into Operational Taxonomic Units (OTU) clustering at $97 \%$ sequence identity. The taxonomical annotation of the OTUs was subsequently performed by CREST using the SILVA database [37]. Data were not rarefied to avoid overlooking rare members of the communities that may be more sensitive to the environmental gradients of interest [39]. Sequence data have been deposited in the European Nucleotide Archive (http://www.ebi.ac.uk/ena) under the accession number PRJEB20838.

\section{Hg methylator community composition: hgcA}

Primers targeting hgcA sequences were adopted from Schaefer et al. [22] and modified to include secondary priming-sequences for a second stage PCR where samplespecific barcodes and Illumina sequencing adaptors were added. For this purpose, the forward primer hgcA_261 F (5'-CGGCATCAAYGTCTGGTGYGC-3') and the reverse primer hgcA_912 R (5'-GGTGTAGGGGGTGCAGCCSG TRWARKT-3') with barcode adaptors, were first used to amplify the $h g c A$ gene from each sample. For the second PCR, each sample was individually barcoded with unique combinations of forward and reverse primers (Supplementary Table 2). For details on the amplification strategy, see Supplementary Fig. 1. Second PCR amplicons were then purified using Agencourt AMPure XP (Beckman Coulter, USA), quantified using the PicoGreen kit (Invitrogen) and subsequently pooled in equal proportions. Amplicons were sequenced using the Illumina MiSeq instrument and pair-end $300 \mathrm{bp}$ mode. Due to the length of the PCR product, only the forward read sequence was used for downstream dataanalysis. Bad quality reads were trimmed with SICKLE [40], and left-over adapters and primers were removed with CUTADAPT [41]. Reads were truncated, dereplicated and singletons removed with USEARCH version 8.0 [42]. The obtained set of reads was then clustered using cd-hit-est with a $60 \%$ similarity threshold [43]. The original qualitycontrolled reads were finally mapped to the representative sequences of the obtained clusters to generate a count table using the USEARCH software. The database used for annotation of the sequences is based on the sequences used by Podar et al. [19], additionally a Hidden Markov Model (HMM) based on these sequences was made using HMMER
[44] and subsequently used to mine $\delta$-Proteobacteria from the IMG database of JGI. The Sequences where curated and the taxonomy homogenized. Analogous to the $16 \mathrm{~S}$ rRNA gene diversity analysis, data were not rarefied. More detailed information on the construction of $h g c A$ gene libraries and phylogenetic analyses is given in Supplementary Information. Sequence data can be found in the European Nucleotide Archive under the accession number PRJEB20838.

\section{Quantitative PCR}

Quantitative PCR (qPCR) of marker genes (16S rRNA, $d s r A, G C S$, $m c r A$, and $m e r A$ ) for key functional groups involved in carbon, sulfur and iron cycling was performed in $10 \mu \mathrm{L}$ total reaction volumes with primer pairs listed in Table S3 using an Eco cycler (Illumina, San Diego, California) and the Kapa SYBR Fast qPCR kit (Kapa Biosystems, Wilmington, Massachusetts), as described in Bravo et al. [45]. All reactions were performed according to the supplier's protocol with 40 amplification cycles and real-time data acquired during the annealing step of each cycle. Standard curves and no-template controls were included in triplicate for each reaction and the target copy number per sample was calculated. The quality of standard curve and melting curves were tested with qpcR package (www.dr-spiess.de/qpcR.html; [46, 47]) in the freely available software environment $\mathrm{R}$ version 3.1 .0 (http://www.r-project.org/). See Supplementary Information for more details.

\section{Statistical analysis}

Pearson correlations were calculated between chemical compounds using centered and reduced values in Excel (Microsoft, Redmond, WA, USA). Rarefaction curves (Supplementary Fig. 2) were plotted using R. Barplots showing relative abundances of major taxa were built with the RAM package (http://cran.r-project.org/package = RAM, [48]).

\section{Results}

\section{Chemical analyses}

The geochemical composition of the 18 sediment samples features gradual changes with depth, but little variation among the 3 replicate sediment cores (Fig. 1; Supplementary Table 4). The decrease of $\mathrm{SO}_{4}{ }^{2-}$ together with increasing $\mathrm{Fe}^{\mathrm{II}}$ and $\mathrm{S}^{0}$ concentrations with depth indicates that $\mathrm{H}_{2} \mathrm{~S}$ produced by $\mathrm{SRB}$ is titrated out from the porewater by Fe ${ }^{\mathrm{III}}$ (Fig. 1, Supplementary Table 4). As a consequence, porewater sulfide concentrations remain low throughout the 


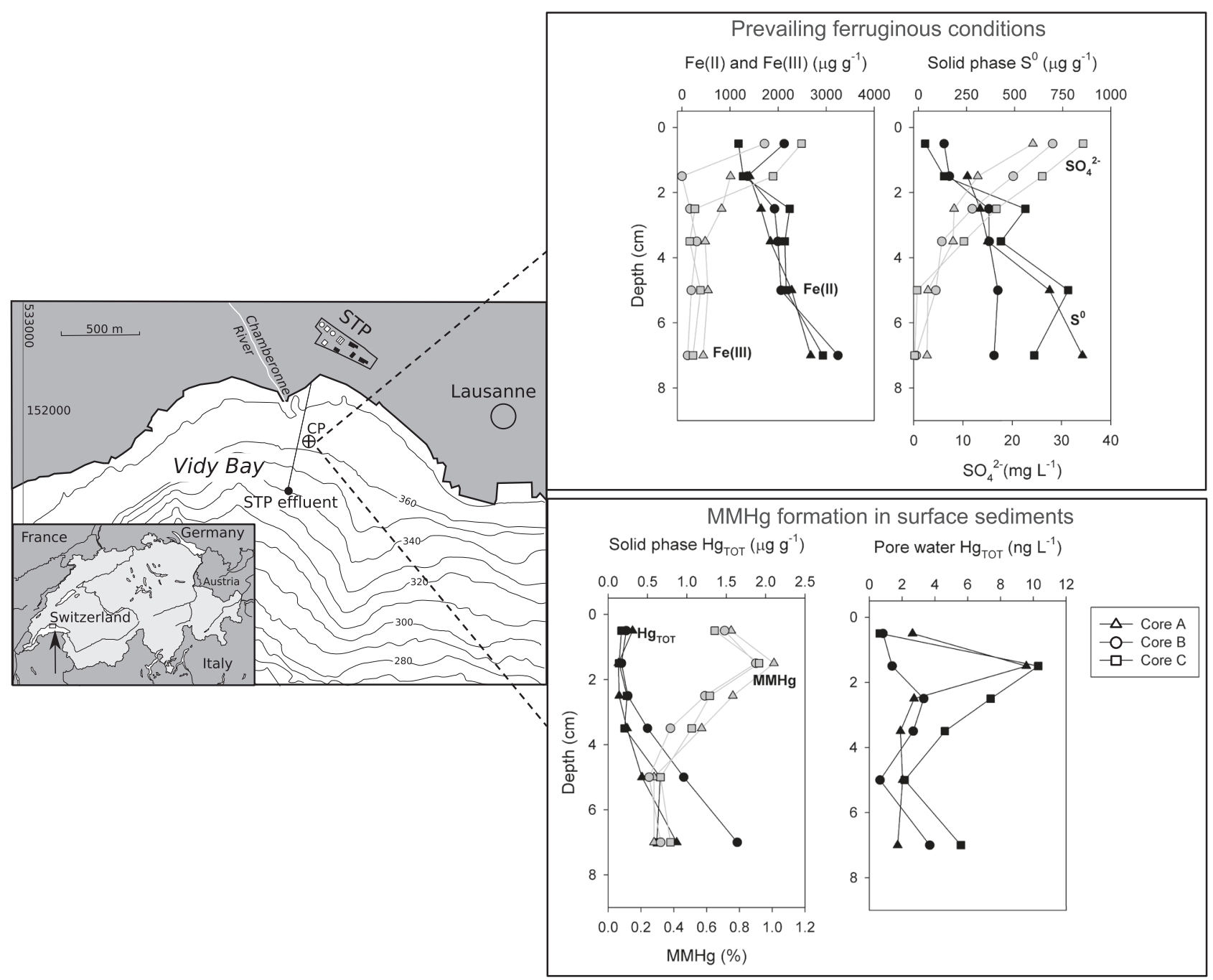

Fig. 1 Map of the study area and chemical characterization of solid phases and porewater in three sediment cores collected at site CP near the outlet pipe of the sewage treatment plant (STP). Complete data are given in Supplementary Table 4.

whole sediment core [2]. Carbon, OM and nitrogen varied only little with depth, with $\mathrm{C}_{\text {org }}$ representing about $40 \%$ of $\mathrm{C}_{\text {tot }}$, OM ranging from 5.5 to $7.2 \%$, and $\mathrm{C}_{\text {org }} / \mathrm{N}$-ratio ranging from 5.5 to 11.3 , indicative of fresh $\mathrm{OM}$ of predominantly microbial and algal origin. Generally, the geochemical conditions are very similar to an earlier study conducted at the same site [2].

$\mathrm{Hg}_{\text {tot }}$ increased with depth from $0.13-1.67 \mu \mathrm{g} \mathrm{g}^{-1}$ d.w. (range of the three core replicates) to $1.73-5.58 \mu \mathrm{g} \mathrm{g}^{-1} \mathrm{~d}$.w. at the deepest layer (Fig. 1). These values are 4- to 50-times higher than the natural background of $\mathrm{Hg}_{\text {tot }}$ in Lake Geneva $\left(0.03 \mathrm{mg} \mathrm{kg}^{-1}\right)$ [49]. MMHg concentrations were generally higher in the surface layer $\left(0-1 \mathrm{~cm}: 1.1-2.3 \mathrm{ng} \mathrm{g}^{-1}\right)$ and in deeper layer (6-8 cm: $\left.2.4-5.2 \mathrm{ng} \mathrm{g}^{-1}\right)$ than at intermediate depth (Fig. 1, Supplementary Table 4). The proportion of $\mathrm{MMHg}$ to $\mathrm{Hg}_{\text {tot }}$ was the highest at $1-2 \mathrm{~cm}(0.9-1.1 \%)$ and decreased with depth to values between $0.28 \%$ and $0.38 \%$. These $\mathrm{Hg}_{\text {tot }}$ values and MMHg percentages are in line with analyses performed previously, but fall within the lower range of $\mathrm{Hg}$ concentrations reported for Vidy Bay [49, 50]. Pearson's correlation analysis revealed that $\mathrm{MMHg}$ concentrations were positively correlated to $\mathrm{C}_{\text {org }}, \mathrm{S}_{\text {tot }}, \mathrm{Fe}^{\mathrm{II}}$ and $\mathrm{Hg}_{\text {tot }}$ (Figure $\mathrm{S} 3$ ). The proportion of $\mathrm{Hg}_{\text {tot }}$ as $\mathrm{MMHg}$ was also correlated with porewater $\mathrm{SO}_{4}{ }^{2-}$ concentration, and inversely to the sedimentary $\mathrm{S}^{0}$ content (Supplementary Fig. 3). Overall, our results confirm the important role of S, Fe and $\mathrm{Hg}$ for the geochemistry in sediments of Vidy Bay [2].

\section{Bacterial community composition: 16S rRNA gene}

The composition and diversity of the combined bacterial community was investigated by sequencing of $16 \mathrm{~S}$ rRNA amplicons. Close to 524'000 sequences (between 13'133 and 59'205 per sample) were clustered into OTUs at three different identity levels; $80 \%$ roughly corresponding to the phylum level, $95 \%$ corresponding to genus-level, and 
Fig. 2 Number of OTU's detected as function of the number of collected sediment samples from Vidy Bay. Plots were made with the specaccum function of the Vegan package in $\mathrm{R}$. The OTU clustering was done at 97 and at $88 \%$ similarity levels for 16S rRNA gene and hgcA gene sequences, respectively.
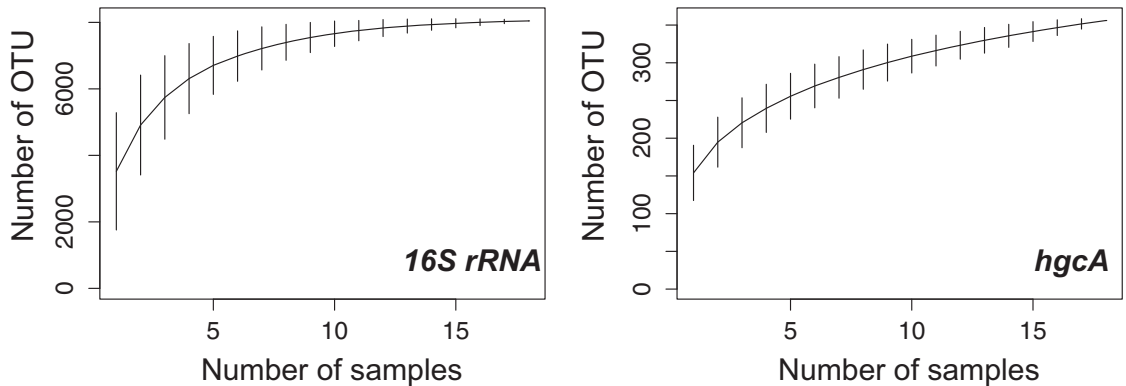

A

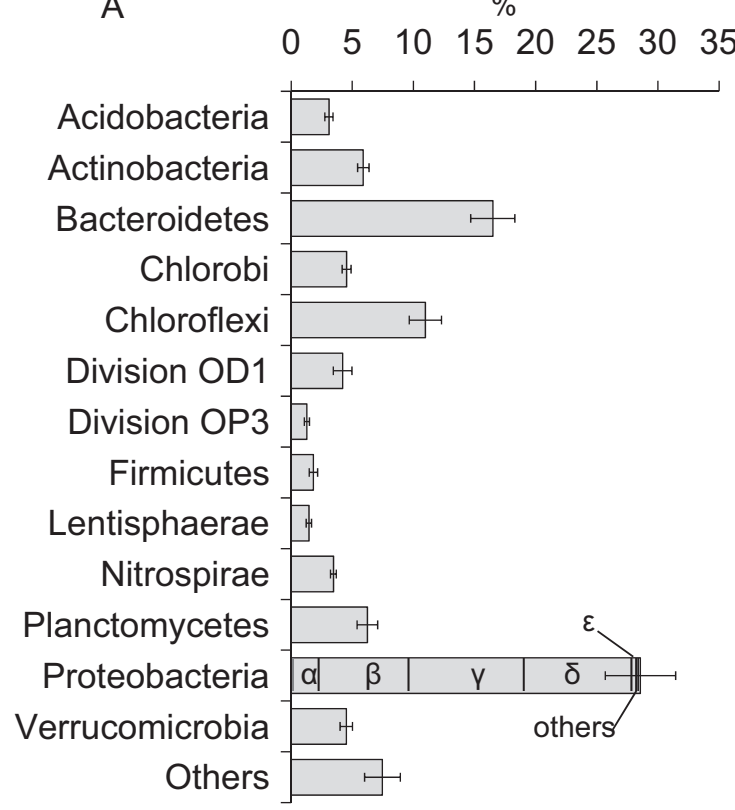

Fig. 3 Phylogenetic distribution of bacterial 16S rRNA gene sequences in the combined Vidy Bay sediment dataset: A. Relative abundance of major phyla and $\mathbf{B}$ classes within the $\delta$-Proteobacteria.

$97 \%$ to species-level, the latter with 8044 OTUs identified. The overall coverage of the sediment community is reflected in the combined richness detected for random subsets of analyzed samples, where the logarithmic shape indicated that most of the species richness occurring in the sediments was covered in the combined dataset (Fig. 2). Overall the bacterial community composition was quite uniform across replicates and samples (Fig. 3, Supplementary Fig. 4), and showed only a slight change in diversity with depth at the OTU level (Supplementary Fig. 5).

Phylogenetic analysis of 16S rRNA gene sequences identified Proteobacteria as the dominant phylum in terms of richness and relative abundance, represented by 1'605 OTUs or $28.6 \pm 1.6 \%$ of the reads, followed by Bacteroidetes ( 629 OTUs, $16.5 \pm 2.4 \%$ ), and Chloroflexi (615 OTUs, $11 \pm$ $2.7 \%$; Fig. 3). Within the Proteobacteria, 8 -Proteobacteria (869 OTUs) were abundant and accounted for $31 \%$ of the

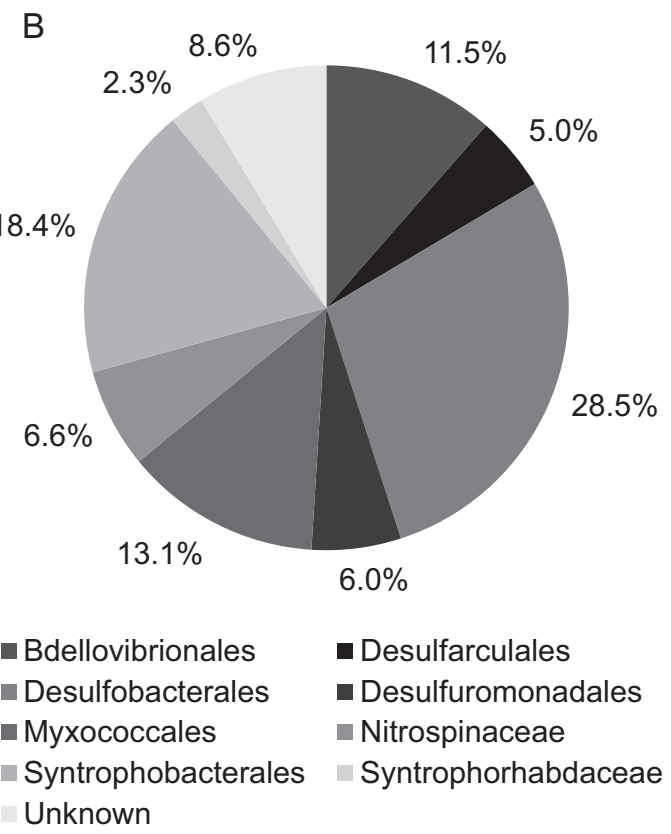

Presented data are average percentages $( \pm \mathrm{SE})$ of reads from the 18 collected samples (6 depths in 3 cores). Categories representing $>1 \%$ are shown.

Proteobacteria reads. Firmicutes, mostly represented by Clostridiales, contributed $1.9 \%$ of the total reads, but had representatives among the 50 most abundant OTUs in the total data set (Supplementary Table 5). Members of the Syntrophobacterales, including, e.g., Syntrophus, Syntrophorhabdus, and Syntrophobacteraceae, were also detected. Moreover, several lineages involved in Fetransformation (e.g., Acidithiobacillus, Geobacter, Geothermobacter, and Shewanella; [51]) and sulfur cycling (e.g., Desulfobulbaceae, Desulfobacteraceae, etc.) were identified. Among the genera known to host representatives that carry hgcAB genes [18, 19], we identified Geobacter, Syntrophus, Syntrophorhabdus, Desulfobulbus, Desulfomonile, Desulfovibrio, Desulfomicrobium, unknown Ruminococcaceae genus, and Syntrophomonadaceae. In particular, Geobacter, Syntrophus, and Syntrophorhabdus represented 0.15, 0.29, and $0.21 \%$ of total $16 \mathrm{~S}$ rRNA reads, respectively. 


\section{Quantification of functional genes}

Quantification of total bacterial abundance by qPCR detected between $1.4 \times 10^{7}$ and $6.4 \times 10^{8} 16 \mathrm{~S}$ rRNA gene copies $\mathrm{g}^{-1}$ of wet sediment (Supplementary Table 6). Abundance of 16S rRNA gene was highest in the uppermost sediment layers and decreased slightly with depth. Analyses of selected functional genes revealed wide occurrences of SRB (dsrA), Geobacteraceae (GCS) and methanogens ( $m c r A$ ) (Supplementary Table 6). The abundance of SRB, Geobacteraceae and merA-encoding the mercuric reductase-slightly decreased with depth. Methanogens reached their highest representation in the deepest sediment layers, where the main electron acceptors $\mathrm{Fe}^{\mathrm{III}}$ and sulfate were depleted (Fig. 1).

\section{A closer look at the $\mathrm{Hg}$-methylating community through hgcA gene analysis}

In addition to the phylogenetic community analysis, the diversity of Hg-methylating microorganisms was for the first time assessed by high-throughput sequencing of the $h g c A$ gene. As for $16 \mathrm{~S}$ rRNA, community rarefaction indicated that most of the $\mathrm{Hg}$ methylator diversity targeted by these primers was captured (Fig. 2). Analogous to $16 \mathrm{~S}$ rRNA, Hgmethylating community composition was also quite uniform across replicates and samples with only minor changes with depth (Fig. 4, Supplementary Fig. 5). The hgcA gene data set consisted of altogether 741' 890 reads ranging from 22 '522 to 62 ' 442 reads per sample. A total of 356 OTUs were identified at $88 \%$ identity level, 325 of which were affiliated with Bacteria, 25 with Archaea, while the affiliation of 6 OTUs could not be resolved. Among the bacterial $h g c A$ OTU's, 264 were annotated as Proteobacteria, 41 as Firmicutes while 20 could not be linked to any specific phylum. In terms of their relative abundance, Bacteria represented $99 \%$ of the reads, while Archaea represented $0.8 \%$ of the reads.

All proteobacterial $h g c A$ reads grouped with $\delta$-Proteobacteria, with $27 \%$ of the reads being Desulfuromonadales (153 OTUs), $71 \%$ were from unknown $\delta$-Proteobacteria $(92$ OTUs) and $0.1 \%$ represented other $\delta$-Proteobacteria, including Desulfovibrionales, Desulfobacterales and Syntrophobacterales (Figure S6). The 17 most abundant hgcA OTUs contributed $92 \%$ of all reads and were all affiliated with $\delta$-Proteobacteria. In particular, the three most abundant OTUs in terms of read counts ("OTU_0032", "OTU_0031" and

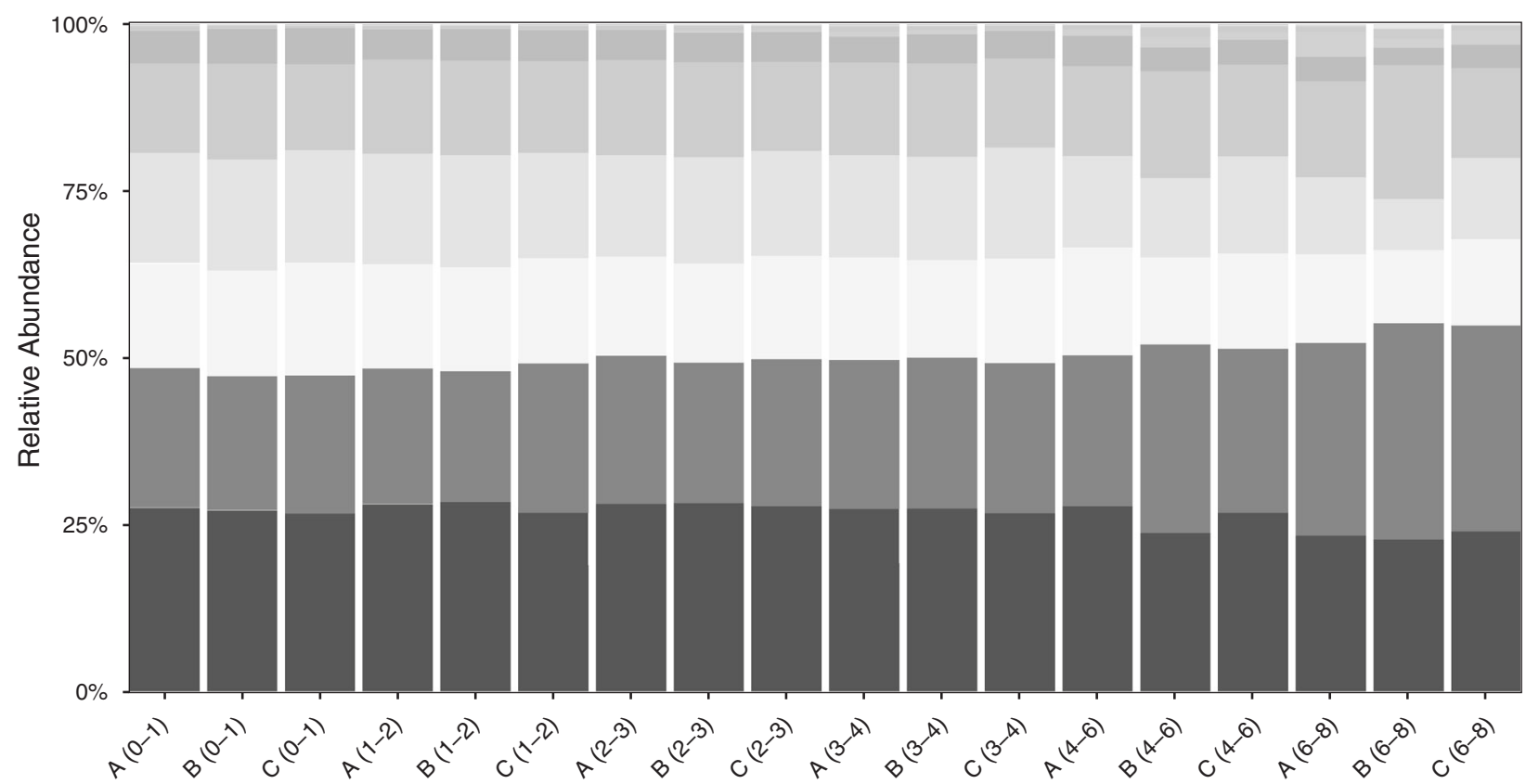

$\mathrm{Hg}$ methylators

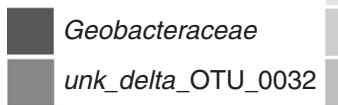

unk_delta_OTU_0031

unk_delta_OTU_0014
unk_delta
unk_delta_OTU_0630
unknown

Methanomassiliicoccaceae
Syntrophomonadaceae
Desulfovibrionaceae
Desulfobulbaceae

Syntrophaceae

Desulfobacteraceae

Chrysiogenaceae

Methanomicrobiaceae
Fig. 4 Relative abundance of $\mathrm{Hg}$-methylating families carrying $\mathrm{hgcA}$ in Vidy Bay sediments. "OTU_0032", "OTU_0031", "OTU_0014", and "OTU_0630", all abundant members of the Hg-methylating community, were annotated as unknown $\delta$-Proteobacteria. Numbers in parentheses represent the sediment depth interval in centimeters. 


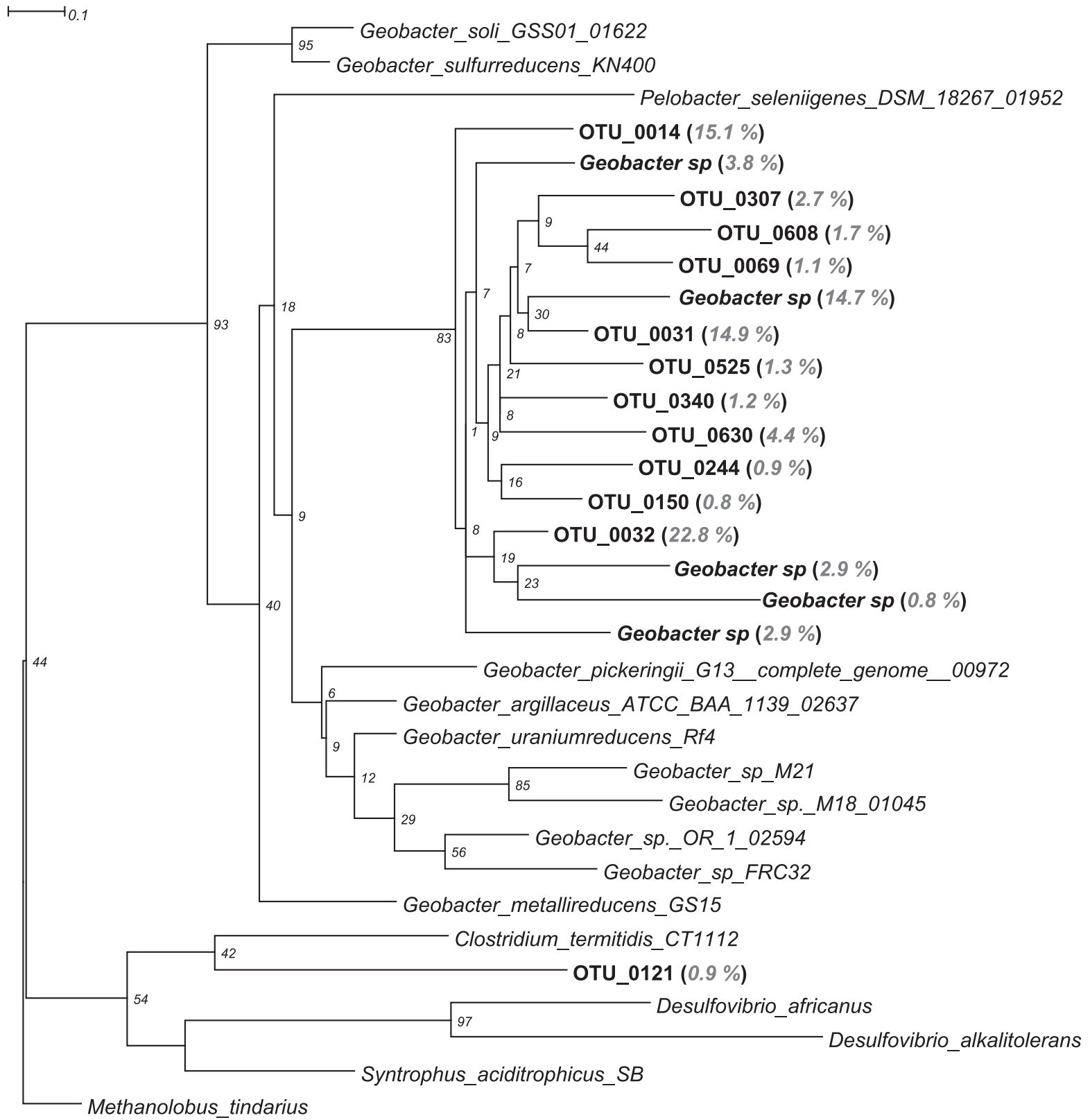

Fig. 5 Phylogenetic distribution of the 17 most abundant $\delta$ Proteobacteria of Vidy Bay sediments (names in bold) based on $h g c A$ sequences. The tree was generated using RAxML (version 8.2.4)

"OTU_0014") were annotated as unknown $\delta$-Proteobacteria and represented $22.8,14.9$, and $15.1 \%$ of the reads, respectively (Fig. 4). The fourth most abundant OTU was affiliated with Geobacter spp. and contributed $14.7 \%$ of reads. In addition, an unknown $\delta$-Proteobacteria "OTU_0630" represented $4.4 \%$ of the reads (Fig. 4). At higher taxonomic resolution, $99 \%$ of the Desulfuromonadales reads were affiliated with Geobacteraceae (147 OTUs, $27 \%$ of all $h g c A$ reads). The two most abundant archaeal $h g c A$ OTUs were affiliated with Methanomassiliicoccus spp. and each with the PROTGAMMLG model and the autoMR to choose the number of necessary bootstraps (750).

represented about $0.3 \%$ of total $h g c A$ reads. These OTUs were 20-112 times more abundant in the $4-6 \mathrm{~cm}$ and $6-8 \mathrm{~cm}$ of sediment than in $0-1 \mathrm{~cm}$ and $1-2 \mathrm{~cm}$ layers (Fig. 4). Hg-methylating Firmicutes were also detected $(0.2 \%$ of reads). In particular, a Dethiobacter sp. (Syntrophomonadaceae) represented $0.1 \%$ of reads, whereas an Ethanoligenens sp. (Ruminococcaceae) accounted for $0.02 \%$ of reads.

Phylogenetic analysis suggested that the most abundant Hg-methylating OTUs (“OTU_0032", “OTU_0031" and 
"OTU_0014") of Vidy Bay sediments were phylogenetically related to Geobacter species (Fig. 5). Therefore, when summing the reads of "OTU_0032", "OTU_0031", "OTU_0014", and "OTU_0630" with those of identified Geobacteraceae, our data suggested that Desulfuromonadales could contribute to more than $85 \%$ of the reads encountered (Fig. 4, Supplementary Fig. 6). Hence unknown Hg-methylating $\delta$-Proteobacteria and unknown Hg-methylating bacteria combined, would account for less than $15 \%$ of the reads (Supplementary Fig. 6). One OTU ("OTU_0121"), representing $0.9 \%$ of reads and initially annotated as $\delta$-Proteobacteria, was more closely related to Clostridium spp. according to the phylogenetic analysis.

\section{Discussion}

\section{WWTP effluents foster specific geochemical conditions that favor $\mathrm{Hg}$ methylation processes}

Effluents of the WWTP with Fe as dephosphatation agent are a known source of $\mathrm{Hg}$ [49] and create geochemical conditions favoring $\mathrm{Hg}$ methylation [2]. Here the highest proportion of $\mathrm{Hg}_{\text {tot }}$ as $\mathrm{MMHg}$ was observed at 1-2 $\mathrm{cm}$ depth (Fig. 1, Table S4). The ferruginous conditions of Vidy Bay sediments, i.e. high porewater $\mathrm{Fe}^{2+}$ concentrations but virtually no dissolved sulfide available to bind $\mathrm{Hg}$ (Fig. 1), most likely keep $\mathrm{Hg}$ bound to OM [52] and thus available for methylation. Also, degradation of specific organic compounds, or reductive dissolution of $\mathrm{Fe}^{\mathrm{III}}$ (oxy)hydroxides under anoxic conditions, likely trigger the release of $\mathrm{Hg}$, as indicated by porewater $\mathrm{Hg}_{\text {tot }}$ peaking at this specific depth and accordingly enhance net $\mathrm{MMHg}$ formation in this layer. Considering that the abundance of functional genes (Supplementary Table 6), bacterial communities (16S rRNA, Figure S4) and the Hg-methylating communities (hgcA, Fig. 4, Supplementary Fig. 6) showed only minor variation over depth across all studied sediment profiles, our results highlight that geochemical conditions prevailing at 1-2 cm depth control MMHg formation. Thus the effluents from the WWTP might not only exert a strong influence on the redox states of $\mathrm{Fe}$ and $\mathrm{S}$ but also on $\mathrm{Hg}$ speciation and cycling.

\section{Geobacteraceae: dominant members of the $\mathbf{H g}$ - methylating guild in ferruginous sediments}

By combined analysis of $16 \mathrm{~S}$ rRNA and $h g c A$ sequences, we identified microorganisms potentially involved in $\mathrm{MMHg}$ production. Here the observed richness and abundance imply that FeRB but also fermenters and other hitherto unknown $\mathrm{Hg}$ methylators are members of the $\mathrm{Hg}$ methylating microbial community in sediments affected by
OM- and Fe-rich WWTP effluents. However, both the $16 \mathrm{~S}$ rRNA gene and $h g c A$ gene analyses showed that $\delta$ Proteobacteria, and in particular Desulfuromonadales, were abundant. Recent studies of $h g c A$ diversity in wetlands and rice paddies have concluded that $\delta$-Proteobacteria dominate Hg-methylating microbial communities [20-22] and this seems to hold also for the freshwater sediments studied here. Although the primers used in these studies were designed based on genomic DNA from a small subset of the known Hg-methylating microorganisms, most of them $\delta$-Proteobacteria, our results demonstrate that $h g c A$ sequencing was also successful in detecting some Archaea (Fig. 4) and members of other bacteria phyla such as Firmicutes. Among $\delta$-Proteobacteria, the richness and the abundance of Geobacter spp. in the hgcA data set pointed to their importance for $\mathrm{Hg}$ methylation in the studied sediments. Only a few previous studies have demonstrated that $\mathrm{Hg}$ methylation in sediments can occur under Fe-reducing conditions with FeRB mediating the process [2, 14, 15]. Instead, SRB have historically been identified as the principal $\mathrm{Hg}$ methylators in aquatic systems [9, 12, 13, 53, 54]. Although we identified several SRB by $16 \mathrm{~S}$ rRNA gene sequencing-with quantification of $d r s A$ gene confirming that SRB are widely present in these sediments-the abundance of identified SRB (e.g., Desulfovibrio spp.) in the $h g c A$ diversity analyses was significantly smaller than for fermenters (e.g., Ruminococcaceae and Syntrophomonadaceae) and FeRB (Geobacteraceae). The latter observation is in line with previous cultivation-based estimates suggesting FeRB to be three orders of magnitude more abundant than SRB in these sediments and that $\mathrm{Fe}^{\mathrm{III}}$ reduction rates was positively correlated to $\mathrm{Hg}$ methylation rates [2].

\section{A geomicrobiological model for coupled Fe, $S$ cycling and $\mathrm{MMHg}$ formation in sediments affected by WWTP discharges}

We propose that FeRB play a central role in both $\mathrm{Hg}$ methylation and anaerobic OM degradation in these sediments. Indeed, Geobacter spp., known to inhabit sediments and sludge [55], can reduce $\mathrm{Fe}^{\mathrm{III}}$ or $\mathrm{S}^{0}$ but also perform interspecies electron transfer to $\mathrm{S}^{0}$-reducers or methanogens [56]. Syntrophic bacteria, however, have been recently identified as putatively important $\mathrm{Hg}$ methylators [21], and have also been detected in sediments adjacent to the WWTP discharge pipe outlet [57]. Accordingly, one known syntrophic lineage, Smithella spp. (Syntrophaceae, 17 reads) was identified in the current $h g c A$ analyses. Some lineages detected in Vidy Bay sediments, such as Syntrophobacteraceae (3574 reads) and Syntrophaceae (5805 reads), might degrade $\mathrm{OM}$ in syntrophic association with $\mathrm{H}_{2}$ consuming organisms, such as FeRB, SRB or methanogens [58, 59]. In 
this context, indirect effects of non-Hg-methylating microorganisms on MMHg formation should also be considered. For example methanogens could maintain the activity of syntrophic $\mathrm{Hg}$ methylators, especially in deeper sediment layers where $\mathrm{Fe}^{\mathrm{III}}$ and $\mathrm{SO}_{4}{ }^{2-}$ are depleted [60]. In short, it is likely that Geobacter sp get enriched by the continuous import of $\mathrm{Fe}^{\mathrm{III}}$ to the sediment surface and continuous reoxidation of $\mathrm{Fe}^{\mathrm{II}}$ at its surface through mixing. In deeper sediment layers, these microbes likely survive through alternative metabolic processes such as $S^{0}$ reduction or syntrophic oxidation of OM [60]. Considering our results here and previous research carried out in Vidy Bay [2], we propose a geomicrobiological model (Figure S7) where Fe reacts with sulfide (either produced by SRB through sulfate reduction or liberated from biomass through anaerobic degradation of amino acids) according to: $2 \mathrm{FeOOH}+$ $\mathrm{HS}^{-}+5 \mathrm{H}^{+} \Rightarrow 2 \mathrm{Fe}^{2+}+\mathrm{S}^{0}+4 \mathrm{H}_{2} \mathrm{O}$. As a result, anoxic conditions prevail in these sediments while sulfide is low and $\mathrm{Fe}^{2+}$ and $\mathrm{S}^{0}$ are high. Elemental sulfur in these sediments might then be recycled by $\mathrm{S}^{0}$-reduction performed by e.g., Geobacter or Dethiobacter [61], which are both identified $\mathrm{Hg}$ methylators [19]. Hence, $\mathrm{Fe}^{\mathrm{III}}$ might act as a direct electron acceptor for Geobacter, but also as an sulfide "scrubber" according to the stoichiometry above and as previously suggested for freshwater sediments (Haveman et al., 2008; [62]). These results provide novel understanding on the role of Geobacter in $\mathrm{Hg}$ methylation processes linked to $\mathrm{Fe}$ and $\mathrm{S}$ cycling in a low-sulfate freshwater environment.

\section{Conclusions}

Previous efforts to identify $\mathrm{Hg}$ methylators have mainly been limited to functional characterization of cultured isolates and inferences made about their close relatives based on phylogenetic markers such as the 16S rRNA gene. A more recent alternative strategy has been to probe directly hgcA genes using target amplification, cloning and sequencing. Here, combination of high-throughput sequencing approach with molecular barcoding and amplification protocols identified $\mathrm{Hg}$-methylating microbial communities in freshwater sediments. Our results reveal the coexistence of a wide abundance of fermenters, secondary fermenters (e.g. syntrophs), SRB, FeRB, and methanogens in this $\mathrm{Hg}$-contaminated freshwater lake ecosystem and point to the significant contribution of syntrophs, fermenters, $\mathrm{Fe}$ and $\mathrm{S}$ reducers to the diversity and abundance of the $\mathrm{Hg}$-methylating community in the sediments rich in $\mathrm{OM}$ and Fe. Moreover, known SRB Hg methylators constituted relatively minor groups compared to the total $\mathrm{Hg}$ methylating and SRB community, supporting the idea that sediments affected by WWTP effluents are in this regard different from most other anoxic aquatic settings previously studied. Our results suggest that geochemical conditions rather than the composition of the resident microbiota dictate net MMHg formation. Since Fe is widely used in waste water treatment across the globe, the importance of $\mathrm{Geo}$ bacteraceae for $\mathrm{Hg}$ methylation and the geochemical conditions reported here are likely relevant for WWTP recipients worldwide.

Acknowledgements We thank Philippe Arpagaus and Alexander Grosse-Honebrink for their help during field-work. Camille Thomas and Daniel Ariztegui are acknowledged for helping with the CHN analyses. This work was supported by the State Secretariat for Education and Research (SER) through grants to C.C. (COST-FA0906 contract no C11.0117), the Swiss National Science Foundation through grants to C.C. (project no 205321_138254 and 200020_157173) and the Swedish Research Council (VR) through grants to A.G.B. (project no 2011-7192) and S.B. (project no 20123892 and 2013-6978).

\section{Compliance with ethical standards}

Conflict of interest The authors declare that they have no conflict of interest.

Open Access This article is licensed under a Creative Commons Attribution 4.0 International License, which permits use, sharing, adaptation, distribution and reproduction in any medium or format, as long as you give appropriate credit to the original author(s) and the source, provide a link to the Creative Commons license, and indicate if changes were made. The images or other third party material in this article are included in the article's Creative Commons license, unless indicated otherwise in a credit line to the material. If material is not included in the article's Creative Commons license and your intended use is not permitted by statutory regulation or exceeds the permitted use, you will need to obtain permission directly from the copyright holder. To view a copy of this license, visit http://creativecommons. org/licenses/by/4.0/.

\section{References}

1. Mason RP, Choi AL, Fitzgerald WF, Hammerschmidt CR, Lamborg $\mathrm{CH}$, Soerensen AL, et al. Mercury biogeochemical cycling in the ocean and policy implications. Environ Res. 2012;119:101-117.

2. Bravo AG, Bouchet S, Guédron S, Amouroux D, Dominik J, Zopfi J. High methylmercury production under ferruginous conditions in sediments impacted by sewage treatment plant discharges. Water Res. 2015;80:245-255.

3. Eckley CS, Watras CJ, Hintelmann H, Morrison K, Kent AD, Regnell O. Mercury methylation in the hypolimnetic waters of lakes with and without connection to wetlands in northern Wisconsin. Can J Fish Aquat Sci. 2005;411:400-411.

4. Gascon Diez E, Loizeau J-L, Cosio C, Bouchet S, Adatte T, Amouroux D, et al. Role of settling particles on mercury methylation in the oxic water column of freshwater systems. Environ Sci Technol. 2016;50:11672-11679.

5. Achá D, Pabón CA, Hintelmann H. Mercury methylation and hydrogen sulfide production among unexpected strains isolated from periphyton of two macrophytes of the Amazon. FEMS Microbiol Ecol. 2012;80:637-45.

6. Gilmour CC, Henry EA, Mitchell R. Sulfate stimulation of mercury methylation in freshwater sediments. Environ Sci Technol. 1992;26:2281-2287. 
7. Hines ME, Poitras EN, Covelli S, Faganeli J, Emili A, Žižek S, et al. Mercury methylation and demethylation in $\mathrm{Hg}$-contaminated lagoon sediments (Marano and Grado Lagoon, Italy). Estuar Coast Shelf Sci. 2012;113:85-95.

8. Avramescu M-L, Yumvihoze E, Hintelmann H, Ridal J, Fortin D, Lean DRS. Biogeochemical factors influencing net mercury methylation in contaminated freshwater sediments from the St. Lawrence River in Cornwall, Ontario, Canada. Sci Total Environ. 2011;409:968-978.

9. Pak K, Bartha R. Mercury methylation and demethylation in anoxic lake sediments and by strictly anaerobic bacteria. Appl Environ Microbiol. 1998;64:1-6.

10. Bridou R, Monperrus M, Gonzalez PR, Guyoneaud R, Amouroux D. Simultaneous determination of mercury methylation and demethylation capacities of various sulfate-reducing bacteria using species-specific isotopic tracers. Environ Toxicol Chem. 2011;30:337-344.

11. Ranchou-Peyruse M, Monperrus M, Bridou R, Duran R, Amouroux D, Salvado JC, et al. Overview of mercury methylation capacities among anaerobic bacteria including representatives of the sulphate-reducers: implications for environmental studies. Geomicrobiol J. 2009;26:1-8.

12. Devereux R, Winfrey MR, Winfrey J, Stahl DA. Depth profile of sulfate-reducing bacterial ribosomal RNA and mercury methylation in an estuarine sediment. FEMS Microbiol Ecol. 1996;20:23-31.

13. Shao D, Kang Y, Wu S, Wong MH. Effects of sulfate reducing bacteria and sulfate concentrations on mercury methylation in freshwater sediments. Sci Total Environ. 2012;424:331-6.

14. Fleming EJ, Mack EE, Green PG, Nelson DC. Mercury methylation from unexpected sources: molybdate-inhibited freshwater sediments and an iron-reducing bacterium. Appl Environ Microbiol. 2006;72:457-464.

15. Yu R-Q, Flanders JR, Mack EE, Turner R, Mirza MB, Barkay T. Contribution of coexisting sulfate and iron reducing bacteria to methylmercury production in freshwater river sediments. Environ Sci Technol. 2012;46:2684-2691.

16. Hamelin S, Amyot M, Barkay T, Wang Y, Planas D. Methanogens: principal methylators of mercury in lake periphyton. Environ Sci Technol. 2011;45:7693-7700.

17. Parks JM, Johs A, Podar M, Bridou R, Hurt RA, Smith SD, et al. The genetic basis for bacterial mercury methylation. Science. 2013;339:1332-1335.

18. Gilmour CC, Podar M, Bullock AL, Graham AM, Brown SD, Somenahally AC, et al. Mercury methylation by novel microorganisms from new environments. Environ Sci Technol. 2013;47:11810-11820.

19. Podar M, Gilmour CC, Brandt CC, Soren A, Brown SD, Crable $\mathrm{BR}$, et al. Global prevalence and distribution of genes and microorganisms involved in mercury methylation. Sci Adv. 2015;1:e1500675.

20. Liu Y-R, Yu R-Q, Zheng Y-M, He J-Z. Analysis of the microbial community structure by monitoring an $\mathrm{Hg}$ methylation gene $\left(h g_{c A}\right)$ in paddy soils along an $\mathrm{Hg}$ gradient. Appl Environ Microbiol. 2014;80:2874-2879.

21. Bae HS, Dierberg FE, Ogram A. Syntrophs dominate sequences associated with the mercury methylation-related gene $h g c A$ in the water conservation areas of the Florida Everglades. Appl Environ Microbiol. 2014;80:6517-6526.

22. Schaefer JK, Kronberg R-M, Morel FMM, Skyllberg U. Detection of a key $\mathrm{Hg}$ methylation gene, $h g c A$, in wetland soils. Environ Microbiol Rep. 2014;6:441-447.

23. Bravo AG, Bouchet S, Tolu J, Björn E, Mateos-Rivera A, Bertilsson S. Molecular composition of organic matter controls methylmercury formation in boreal lakes. Nat Commun. 2017;8:14255.

24. Gibbs-Eggar Z, Jude B, Dominik J, Loizeau J, Oldfield F. Possible evidence for dissimilatory bacterial magnetite dominating the magnetic properties of recent lake sediments. Earth Planet Sci Lett. 1999;168:1-6.

25. Poté J, Haller L, Loizeau J-L, Garcia Bravo A, Sastre V, Wildi W. Effects of a sewage treatment plant outlet pipe extension on the distribution of contaminants in the sediments of the Bay of Vidy, Lake Geneva, Switzerland. Bioresour Technol. 2008;99:7122-7131.

26. Percak-Dennett EM, Loizeau J-L, Beard BL, Johnson CM, Roden EE. Iron isotope geochemistry of biogenic magnetite-bearing sediments from the Bay of Vidy, Lake Geneva. Chem Geol. 2013;360-361:32-40.

27. Loizeau J-L, Pardos M, Monna F, Peytremann C, Haller L, Dominik J. The impact of a sewage treatment plant's effluent on sediment quality in a small bay in Lake Geneva (SwitzerlandFrance). Part 2: Temporal evolution of heavy metals. Lakes Reserv Res Manag. 2004;9:53-63.

28. Dean WE. Determination of carbonate and organic matter in calcareous sediments and sedimentary rocks by loss on ignition: comparison with other methods. J Sediment Res. 1974;44:242-248.

29. Liu B, Yan H, Wang C, Li Q, Guédron S, Spangenberg JE, et al. Insights into low fish mercury bioaccumulation in a mercurycontaminated reservoir, Guizhou, China. Environ Pollut. 2012;160:109-117.

30. Bloom N, Fitzgerald WF. Determination of volatile mercury species at the picogram level by low-temperature gas chromatography with cold-vapour atomic fluorescence detection. Anal Chim Acta. 1988;208:151-161.

31. Rodriguez Martín-Doimeadios RC, Monperrus M, Krupp E, Amouroux D, Donard OFX. Using speciated isotope dilution with GC-inductively coupled plasma MS to determine and unravel the artificial formation of monomethylmercury in certified reference sediments. Anal Chem. 2003;75:3202-3211.

32. Thamdrup B, Fossing H, Jorgensen BB. Manganese, iron, and sulfur cycling in a coastal marine sediment, Aarhus Bay, Denmark. Geochim Cosmochim Acta. 1994;58:5115-5129.

33. Zopfi J, Böttcher ME, Jørgensen BB. Biogeochemistry of sulfur and iron in Thioploca-colonized surface sediments in the upwelling area off central Chile. Geochim Cosmochim Acta. 2008;72:827-843.

34. Regier N, Frey B, Converse B, Roden E, Grosse-Honebrink A, Bravo AG, et al. Effect of Elodea nuttallii roots on bacterial communities and $\mathrm{MMHg}$ proportion in a $\mathrm{Hg}$ polluted sediment. PLoS ONE. 2012;7:e45565.

35. Klindworth A, Pruesse E, Schweer T, Peplies J, Quast C, Horn M, et al. Evaluation of general $16 \mathrm{~S}$ ribosomal RNA gene PCR primers for classical and next-generation sequencing-based diversity studies. Nucleic Acids Res. 2013;41:1-11.

36. Logares R, Lindström ES, Langenheder S, Logue JB, Paterson H, Laybourn-Parry J, et al. Biogeography of bacterial communities exposed to progressive long-term environmental change. ISME J. 2013;7:937-948.

37. Sinclair L, Osman OA, Bertilsson S, Eiler A. Microbial community composition and diversity via $16 \mathrm{~S}$ rRNA gene amplicons: Evaluating the Illumina platform. PLoS ONE. 2015;10:e0116955.

38. Andrews S. (2012). FastQC: A quality control tool for high throughput sequence data. Available online at: http://www. bioinformatics.bab.

39. McMurdie PJ, Holmes S. Waste not, want not: Why rarefying microbiome data is inadmissible McHardy AC (ed). PLoS Comput Biol. 2014;10:e1003531.

40. Joshi NA, Fass JN. (2011). Sickle: A sliding-window, adaptive, quality-based trimming tool for FastQ files.

41. Martin M. Cutadapt removes adapter sequences from highthroughput sequencing reads. EMBnet J. 2011;17:10-12.

42. Edgar RC. UPARSE: highly accurate OTU sequences from microbial amplicon reads. Nat Methods. 2013;10:996-998. 
43. Fu L, Niu B, Zhu Z, Wu S, Li W. CD-HIT: Accelerated for clustering the next-generation sequencing data. Bioinformatics. 2012;28:3150-3152.

44. Eddy SR. Accelerated profile HMM searches. PLoS Comput Biol. 2011;7:e1002195.

45. Bravo AG, Loizeau JL, Dranguet P, Makri S, Björn E, Ungureanu VG et al. Persistent $\mathrm{Hg}$ contamination and occurrence of $\mathrm{Hg}$ methylating transcript $(h g c A)$ downstream of a chlor-alkali plant in the Olt River (Romania). Environ Sci Pollut Res. 2016;11:10529-10541.

46. Ritz C, Spiess AN. qpcR: An R package for sigmoidal model selection in quantitative real-time polymerase chain reaction analysis. Bioinformatics. 2008;24:1549-1551.

47. Tichopad A, Dilger M, Schwarz G, Pfaffl M. Standardized determination of real-time PCR efficiency from a single reaction set-up. Nucleic Acids Res. 2003;31:122-122.

48. Chen W, Simpson J, Levesque C. (2016). RAM: R for ampliconsequencing-based microbial-ecology. $\mathrm{R}$ package version 1.2.1.3.

49. Bravo AG, Bouchet S, Amouroux D, Poté J, Dominik J. Distribution of mercury and organic matter in particle-size classes in sediments contaminated by a waste water treatment plant: Vidy Bay, Lake Geneva, Switzerland. J Environ Monit. 2011;13:974-982.

50. Gascon Diez E, Bravo AG, Porta N, Masson M, Graham ND, Stoll S, et al. Influence of a wastewater treatment plant on mercury contamination and sediment characteristics in Vidy Bay (Lake Geneva, Switzerland). Aquat Sci. 2014;76:21-32.

51. Weber KA, Achenbach LA, Coates JD. Microorganisms pumping iron: anaerobic microbial iron oxidation and reduction. Nat Rev Microbiol. 2006;4:752-764.

52. Liem-Nguyen V, Skyllberg U, Björn E. Thermodynamic modelling of the solubility and chemical speciation of mercury and methylmercury driven by organic thiols and micromolar sulfide concentrations in boreal wetlands. Environ Sci Technol. 2017;51:3678-3686.

53. Bravo AG, Cosio C, Amouroux D, Zopfi J, Chevalley P-A, Spangenberg JE, et al. Extremely elevated methyl mercury levels in water, sediment and organisms in a Romanian reservoir affected by release of mercury from a chlor-alkali plant. Water Res. 2014;49:391-405.

54. Compeau GC, Bartha R. Sulfate-Reducing Bacteria: principal methylators of mercury in anoxic estuarine sediment. Appl Environ Microbiol. 1985; 50(2):498-502.

55. McInerney MJ, Struchtemeyer CG, Sieber J, Mouttaki H, Stams AJM, Schink B, et al. Physiology, ecology, phylogeny, and genomics of microorganisms capable of syntrophic metabolism. Ann NY Acad Sci 2008;1125:58-72.

56. Lovley DR, Ueki T, Zhang T, Malvankar NS, Shrestha PM, Flanagan KA et al. Geobacter: The microbe electric's physiology, ecology, and practical applications.Adv Microb Physiol. 2011;59:1-100.

57. Haller L, Tonolla M, Zopfi J, Peduzzi R, Wildi W, Poté J. Composition of bacterial and archaeal communities in freshwater sediments with different contamination levels (Lake Geneva, Switzerland). Water Res. 2011;45:1213-1228.

58. Chen S, Liu X, Dong X. Syntrophobacter sulfatireducens sp. nov., a novel syntrophic, propionate-oxidizing bacterium isolated from UASB reactors. Int J Syst Evol Microbiol. 2005;55:1319-1324.

59. Bok FAM, Stams AJM, Dijkema C, Boone DR. Pathway of propionate oxidation by a syntrophic culture of Smithella propionica and Methanospirillum hungatei. Appl Environ Microbiol. 2001;67:1800-1804.

60. Holmes DE, Shrestha PM, Walker DJF, Dang Y, Nevin KP, Woodard TL et al. Metatranscriptomic evidence for direct interspecies electron transfer between Geobacter and Methanothrix species in methanogenic rice paddy soils. Appl Environ Microbiol. 2017; 83:e9 e00223-17.

61. Poser A, Lohmayer R, Vogt C, Knoeller K, Planer-Friedrich B, Sorokin D, et al. Disproportionation of elemental sulfur by haloalkaliphilic bacteria from soda lakes. Extremophiles. 2013;17:1003-1012.

62. Hansel CM, Lentini CJ, Tang Y, Johnston DT, Wankel SD, Jardine PM. Dominance of sulfur-fueled iron oxide reduction in lowsulfate freshwater sediments. ISME J. 2015;9:2400-2412. 